\title{
Bone Mineral Content and Bone Mineral Density Are Lower in Older Than in Younger Females With Rett Syndrome
}

\author{
KATHLEEN J. MOTIL, KENNETH J. ELLIS, JUDY O. BARRISH, ERWIN CAEG, AND DANIEL G. GLAZE \\ USDA/ARS Children's Nutrition Research Center [K.J.M., K.J.E.], Departments of Pediatrics [K.J.M., K.J.E., J.O.B., E.C., D.G.G.] \\ and Neurology [D.G.G.], Baylor College of Medicine, Houston, Texas 77030
}

\begin{abstract}
Although bone mineral deficits have been identified in Rett syndrome (RTT), the prevalence of low bone mineral density (BMD) and its association with skeletal fractures and scoliosis has not been characterized fully in girls and women with RTT. Accordingly, we measured total body bone mineral content (BMC) and BMD using dual energy $\mathrm{x}$-ray absorptiometry in a cross-sectional group of 50 females, aged 2-38 y, with RTT. Methyl-CpG-binding 2 (MECP2) mutations, skeletal fractures, and scoliosis were documented. The prevalence of BMC and BMD $z$ scores $<-2$ SD was 59 and $45 \%$, respectively. Although absolute BMC and BMD increased significantly with increasing age, BMC, and BMD $z$ scores were significantly lower in older than in younger females. The prevalence of fractures and scoliosis was 28 and 64\%, respectively. Low BMD $z$ scores were positively associated with fractures and scoliosis. Deficits in BMD were identified across a broad range of $M E C P 2$ mutations. This study identified associations among low BMD, fractures, and scoliosis, and underscored the need for better understanding of the molecular mechanisms of $M E C P 2$ in the regulation of bone mineral metabolism. (Pediatr Res 64: 435-439, 2008)
\end{abstract}

B one mineral deficits complicate the clinical course of Rett syndrome (RTT) (1-3), an X-linked neurodevelopmental disorder caused by mutations in the methyl-CpG-binding 2 (MECP2) gene (4). Consequently, girls with RTT are at increased risk for skeletal fractures $(1,3)$. The etiology of bone mineral deficits is unknown, although impaired ambulation and anticonvulsant therapy have been implicated as causally related factors (3). We have shown that bone mineral deficits are present, despite adequate dietary calcium $(\mathrm{Ca})$ intake, increased intestinal $\mathrm{Ca}$ absorption, and the absence of vitamin D deficiency or hyperparathyroidism (5). Our studies $(5,6)$ and that of Haas et al. (1) documented early, profound deficits of total body bone mineral content (BMC) and bone mineral density (BMD) in girls with RTT compared with unaffected girls and children with other neurologic disorders. Haas et al. (1) showed that total body BMC did not improve with advancing age, whereas our study suggested that the accretion of total body BMC throughout child-

Received December 10, 2007; accepted May 6, 2008

Correspondence: Kathleen J. Motil, M.D., Ph.D., Children's Nutrition Research Center, 1100 Bates Street, Houston, TX 77030; e-mail: kmotil@bcm.edu

Supported in part with federal funds from the Agricultural Research Service of the United States Department of Agriculture under Cooperative Agreement number 625051000; the National Institutes of Health, M01-RR00188 General Clinical Research Center; and with funds provided by the Rett Syndrome Association of Illinois and The Blue Bird Circle.

The contents of this publication do not necessarily reflect the views or policies of the United States Department of Agriculture, nor does mention of trade names, commercial products, or organizations imply endorsement by the United States government. hood was possible (5). All of these studies were limited because of the small number and narrow age range of the participants $(1,5,6)$. They also captured total body BMC and BMD when less emphasis was placed on the nutritional and physical rehabilitation of females with RTT.

In the present study, we expanded the number and age range of the participants and used body composition and ambulation as proxies for nutritional status and physical activity to better understand the prevalence of bone mineral deficits and the relation between bone mineral deficits, MECP2 mutations, and occurrence of bone-related disorders in RTT. We hypothesized that: 1) the early decrease in BMC and BMD persists over time in a cross-sectional cohort of females with RTT, 2) bone mineral deficits occur across a range of $M E C P 2$ mutations, and 3) the reduction in BMC and BMD correlates with the occurrence of fractures and scoliosis. We anticipated that this study would facilitate the development of strategies to promote bone mineral health in RTT.

\section{SUBJECTS AND METHODS}

Subjects. Fifty females who met the clinical criteria for RTT were enrolled (7). MECP2 mutations, if known, were recorded. All participants were female because males with $M E C P 2$ mutations have a different phenotype and rarely meet the diagnostic clinical criteria (8). The eligible age range was $0-40 \mathrm{y}$, with individuals divided among groups of 5-y intervals. Individuals were excluded if they received oral Ca supplements 6 mo before study, had previous therapy with bis-phosphonates, had hypocalcemia, hyperparathyroidism, vitamin D deficiency, or had scoliosis requiring spinal rod placement, the latter because metal interferes with the ability of DXA to provide an accurate assessment of spine BMD.

Parents gave permission for the participation of their daughters in the research study. Assent was waived for the participants because of their cognitive impairment. The Institutional Review Board for Baylor College of Medicine approved the study protocol.

Procedures. All females with RTT were admitted overnight to the General Clinical Research Center, Texas Children's Hospital, for 1) review of their medical history, 2) physical examination, and 3) determination of their stature and body habitus, bone age, and total body and regional bone mineral status. Individual MECP2 mutations were classified as missense, early truncation, late truncation, and large deletion mutations (9). A history of fractures, seizures and anticonvulsant use, the ability to ambulate, and the presence of scoliosis were documented.

Height was measured using a fixed stadiometer or horizontal length board with a movable foot piece (Harpenden, Crymych, Great Britain). Weight was measured using an electronic balance (Scale-Tronix, Inc., Wheaton, IL). Body mass index (BMI) was calculated as weight divided by height squared. Height, weight, and BMI measurements were converted to $z$ scores based on the National Center

Abbreviations: BMC, bone mineral content; BMD, bone mineral density; DXA, dual-energy x-ray absorptiometry; $\mathbf{M E C P 2}$, methyl-CpG-binding protein 2; RTT, Rett syndrome 
for Health Statistics normative data (10). Body fat, as a proportion of body weight, was estimated from triceps, biceps, subscapular, and suprailiac skinfold thickness (11). The bone age of females, age $20 \mathrm{y}$ or less, was calculated from an $\mathrm{X}$-ray of the right hand using reference standards (12).

Whole body, hip, and spine BMC and BMD were measured by dualenergy x-ray absorptiometry (DXA) (Delphi-A System, Hologic, Inc., Madison, WI) using standardized scan protocols. Midazolam $(0.2 \mathrm{mg} / \mathrm{kg} / \mathrm{dose})$ was administered i.v. immediately before the scan to prevent repetitive involuntary movements that could invalidate the analysis. The data from 10 body regions were summed to provide values for total body BMC and BMD; lean body mass; and body fat using body composition software (Delphi-A System, Version 11.2, Hologic, Inc., Waltham, MA). The in vivo precision for BMC and BMD measurements is $2-3 \%$ for children and young adults (13).

Bone mineral status was expressed as BMC, which reflects bone mass, and BMD, which reflects a calculated measure of areal density, not a true volumetric density (14). Because areal density is dependent on bone size, thinning of the bone cortex and a smaller outer diameter of bone may result in diminished areal BMD, whether or not true volumetric density is diminished. To correct for changes in bone size as a function of age and body size, total body BMC and BMD were converted to $z$ scores based on values measured in a reference population (13). The reference database includes DXA scans for more than 2200 healthy children for whom ethnic, racial, and gender distributions are approximately equal. These data were used to develop a predictive algorithm for normative total body BMC and BMD based on age, gender, ethnicity, race, and height (6). For individuals whose ages exceeded $20 \mathrm{y}$, adult references provided with the DXA instrument were used. A significant bone mineral deficit was defined as total body BMD $z$ score $<-2$ SD (15).

Statistical analysis. Sample size was determined from an analysis of females, age 5-12 y, with RTT (6) whose BMC averaged $458 \pm 111 \mathrm{~g}$ and unaffected girls, ages $6-10,11-14$, and $15-18$ y whose BMC averaged $775 \pm$ 233, $1346 \pm 312$, and $1979 \pm 289 \mathrm{~g}$, respectively (13). Seven individuals within each 5-y age category allowed us to detect differences in BMC between females with RTT and the reference population of 1 SD at a significance of 0.05 and power of 0.8 .

Descriptive statistics were calculated using Minitab software (Version 11.0, Minitab Statistical Software, Inc., State College, PA). One-sample $t$ tests were used to detect differences in height, weight, BMI, BMC, and BMD $z$ scores between the RTT cohort and reference population $(10,13)$. Linear regression was applied to characterize relations: 1) between methods used to estimate the proportion of body fat in the RTT cohort; 2) among the variables: lean body mass, body fat, bone age, total body BMC, total body BMD, and age, and 3) among the variables spine, hip, and total body BMC and BMD. Two-sample $t$ tests were used to detect differences in lean body mass, body fat, and BMC between girls with RTT and the reference population at age-specific intervals (13). Two-sample $t$ tests were used to detect differences in BMC and BMD $z$ scores within the RTT cohort, based on gene mutations, occurrence of fractures and scoliosis, seizure and medication history, and ambulatory status. $\chi^{2}$ analysis was used to detect differences in the occurrence of fractures and scoliosis between individuals with and without bone mineral deficits. Significance was determined at $p<0.05$.

\section{RESULTS}

Characteristics of the RTT cohort. The age range of the RTT cohort was 2-38 y (Table 1). The racial and ethnic distribution was predominantly Caucasian. MECP2 mutations were identified in $90 \%$ of the cohort, the most common being missense and early truncation mutations. Height, weight, and BMI $z$ scores were $<2$ SD in 50,48 , and $28 \%$, respectively of the RTT cohort. Mean $z$ scores for height, weight, and BMI, were significantly lower than those of the reference population (10). Fractures and scoliosis occurred in 28 and $64 \%$ of the cohort, respectively. Fifty percent of the cohort used anticonvulsants and $74 \%$ were ambulatory at the time of study.

BMC and density measures. Total body BMC and BMD $z$ scores were $<-1 \mathrm{SD}$ in at least three fourths of the RTT cohort and $<-2$ SD in approximately one half of the RTT cohort (Table 2). Mean $z$ scores for total body BMC and BMD were significantly lower in the RTT cohort than in the reference population (13). After adjusting for age, BMD, but not BMC, of African American females with RTT tended to be greater than their Caucasian, Hispanic, and Asian counterparts $(0.857 \pm 0.081$ versus $0.786 \pm 0.090,0.789 \pm 0.079$, and $0.758 \pm 0.082 \mathrm{~g} / \mathrm{cm}^{2}$, respectively; $\left.p<0.07\right)$. Total body $\mathrm{BMC}\left[\mathrm{BMC}_{(\mathrm{g})}=32+87 \operatorname{age}_{(\mathrm{y})}-1.4 \operatorname{age}_{(\mathrm{y})}{ }^{2} ; p<0.001, r=\right.$ $0.87]$ and $\mathrm{BMD}\left[\mathrm{BMD}_{\left(\mathrm{g} / \mathrm{cm}^{2}\right)}=0.54+0.025 \mathrm{age}_{(\mathrm{y})}-0.0004\right.$ $\left.\operatorname{age}_{(\mathrm{y})}{ }^{2} ; p<0.001, r=0.85\right]$ increased with advancing age. However, within each comparative age group, total body BMC was significantly lower in the RTT cohort than in the reference population (Fig. 1A) (13). Total body BMC (Fig. $2 A$ ) and BMD (Fig. $2 B$ ) $z$ scores decreased significantly over the age range of the RTT cohort. Hip BMC (Fig. $3 A$ ) and BMD (Fig. $3 B$ ) were associated significantly with total body BMC and BMD, respectively. Spine BMC $(p<0.001, r=$ $0.94)$ and $\operatorname{BMD}(p<0.001, r=0.96)$ were associated with total body BMC and BMD, respectively. Bone age was similar to chronological age in individuals younger than age $20 \mathrm{y}(p<$ 0.001, $r=0.97$ ).

Body composition measures. Lean body mass and body fat comprised $66 \pm 7 \%$ and $31 \pm 7 \%$ of body weight, respec-

Table 1. Characteristic features of girls and women $(n=50)$ with Rett syndrome*

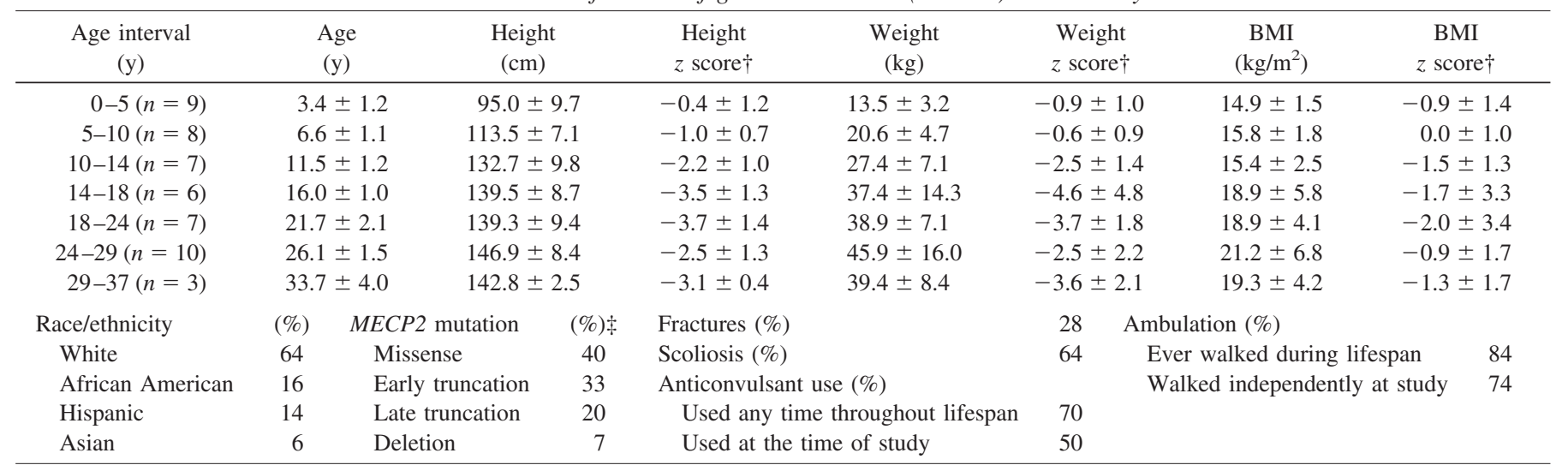

* Expressed as mean $\pm \mathrm{SD}$ where appropriate.

$\dagger p<0.05$, different from the National Center for Health Statistics data (10).

\$ Individuals with positive $M E C P 2$ mutation $(n=45)$. 
Table 2. Characteristic features of body composition of girls and women $(n=50)$ with Rett syndrome

\begin{tabular}{ccc}
\hline & $\begin{array}{c}\text { No. } \\
\text { Vabjects* }\end{array}$ & Value $\dagger$ \\
\hline Bone mineral content & & \\
Total body $(\mathrm{g})$ & 49 & $850 \pm 466$ \\
$(z$ score $)$ & 49 & $-2.2 \pm 1.0 \ddagger$ \\
$(\%<-1 \mathrm{SD})$ & 49 & 84 \\
$(\%<-2 \mathrm{SD})$ & 49 & 59 \\
Spine $(\mathrm{g})$ & 46 & $22 \pm 13$ \\
Hip $(\mathrm{g})$ & 47 & $9.8 \pm 5.8$ \\
Bone mineral density & & \\
Total body $\left(\mathrm{g} / \mathrm{cm}^{2}\right)$ & 49 & $0.792 \pm 0.140$ \\
$(z$ score $)$ & 49 & $-1.7 \pm 1.2 \ddagger$ \\
$(\%<-1$ SD) & 49 & 76 \\
$(\%<-2$ SD) & 49 & 45 \\
Spine $\left(\mathrm{g} / \mathrm{cm}^{2}\right)$ & 46 & $0.597 \pm 0.213$ \\
Hip (g/cm $\left.{ }^{2}\right)$ & 47 & $0.471 \pm 0.145$ \\
Lean body mass $(\mathrm{kg})$ & 46 & $19.6 \pm 8.4$ \\
$(\%$ body weight $)$ & 46 & $66 \pm 7$ \\
Body fat $(\mathrm{kg})$ by DXA & 46 & $10.1 \pm 7.2$ \\
$(\%$ body weight $)$ & 46 & $31+7$ \\
Body fat $(\mathrm{kg})$ by & 50 & $10.1 \pm 6.5$ \\
anthropometry $\$$ & & \\
$(\%$ body weight $)$ & 50 & $30.9 \pm 4.5$ \\
\hline
\end{tabular}

* One individual unknowingly had metal devices in spine and hip; movement artifact prevented estimates of the components of body composition in some subjects.

$\dagger$ Values expressed as mean \pm SD where appropriate.

$\$ p<0.05$, different from the reference population (13)

$\S$ Determined from the sum of triceps, biceps, subscapular, and suprailiac skinfold thicknesses (11)

tively, in the RTT cohort (Table 2). The proportion of body fat obtained by DXA correlated positively with that obtained from the thickness of four skinfolds $(p<0.001, r=0.80)$. Lean body mass [lean body $\operatorname{mass}_{(\mathrm{kg})}=3.74+1.69$ $\operatorname{age}_{(\mathrm{y})}-0.03 \operatorname{age}_{(\mathrm{y})}{ }^{2}, p<0.001, r=0.85$ ] and body fat [body $\mathrm{fat}_{(\mathrm{kg})}=0.33+1.09 \operatorname{age}_{(\mathrm{y})}-0.02 \operatorname{age}_{(\mathrm{y})}{ }^{2} ; p<0.01, r=$ $0.56]$ increased with advancing age. However, within each age group, the lean body mass (Fig. 1B), but not body fat (Fig. $1 C$ ), was significantly lower in the RTT cohort than in the reference population (13). When expressed as a proportion of body weight, body fat was higher for girls with RTT, aged 3-5 y $(30 \pm 4 \%$ versus $21 \pm 5 \%, p<0.001)$ and $6-10$ y $(33 \pm$ $7 \%$ versus $23 \pm 8 \%, p<0.01)$ than that of the respective reference groups, but not for girls with RTT, aged 11-14 y $(23 \pm 12 \%$ versus $27 \pm 8 \%)$ and $15-18$ y $(32 \pm 9 \%$ versus $27 \pm 6 \%$ ) (13). When adjusted for age, the accretion of bone
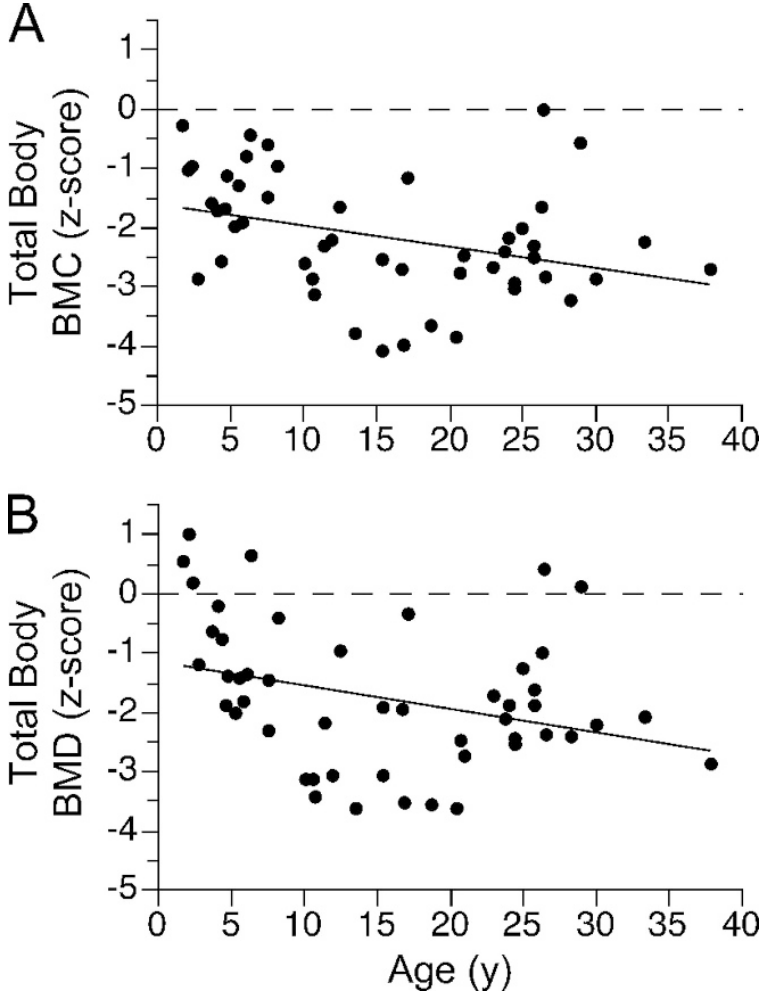

Figure 2. Relation between total body BMC or BMD and age in girls and women $(n=50)$ with Rett syndrome: $(A)$ total body $\mathrm{BMC}_{(z \text { score })}=-0.85-$ $0.17 \operatorname{age}_{(\mathrm{y})}+0.004 \operatorname{age}_{(\mathrm{y})}{ }^{2} ; p<0.01, r=-0.45 ;(B)$ total body $\mathrm{BMD}_{(z \text { score })}=$ $-0.12-0.22 \operatorname{age}_{(\mathrm{y})}+0.005 \operatorname{age}_{(\mathrm{y})}{ }^{2} ; p<0.01, r=-0.46$.

mineral content was associated positively with the lean body mass ( $p<0.001, r=0.97)$, but not body fat.

Mutational analysis. Total body BMC and BMD $z$ scores were not significantly different among the classes of gene mutations.

Anticonvulsants and ambulation. Total body BMC and BMD $z$ scores were significantly lower in those who had seizures than in those who did not (Table 3). Total body BMC and BMD $z$ scores were significantly lower in those who received anticonvulsants previously, but not at the time of study, than in those who did not. Total body BMC and BMD $z$ scores did not differ between females who ambulated independently and those who walked with assistance or never walked.

Skeletal fractures and scoliosis. An age effect was apparent for both fractures and scoliosis in the RTT cohort; females with fractures $(20.3 \pm 6.7$ versus $13.6 \pm 10.1 \mathrm{y}, p<0.01)$ and/or
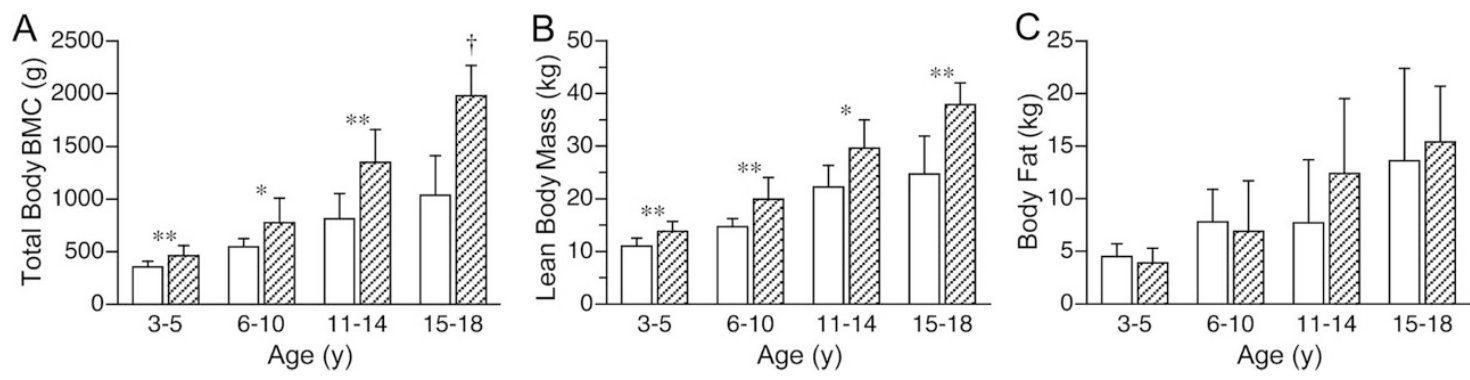

Figure 1. Body composition of girls $(n=50)$ with Rett syndrome $(\square)$ and an age-matched reference population (שC): $(A)$ total body BMC, $(B)$ lean body mass, (C) body fat; * $p<0.05, * * p<0.01, \dagger p<0.001$ 

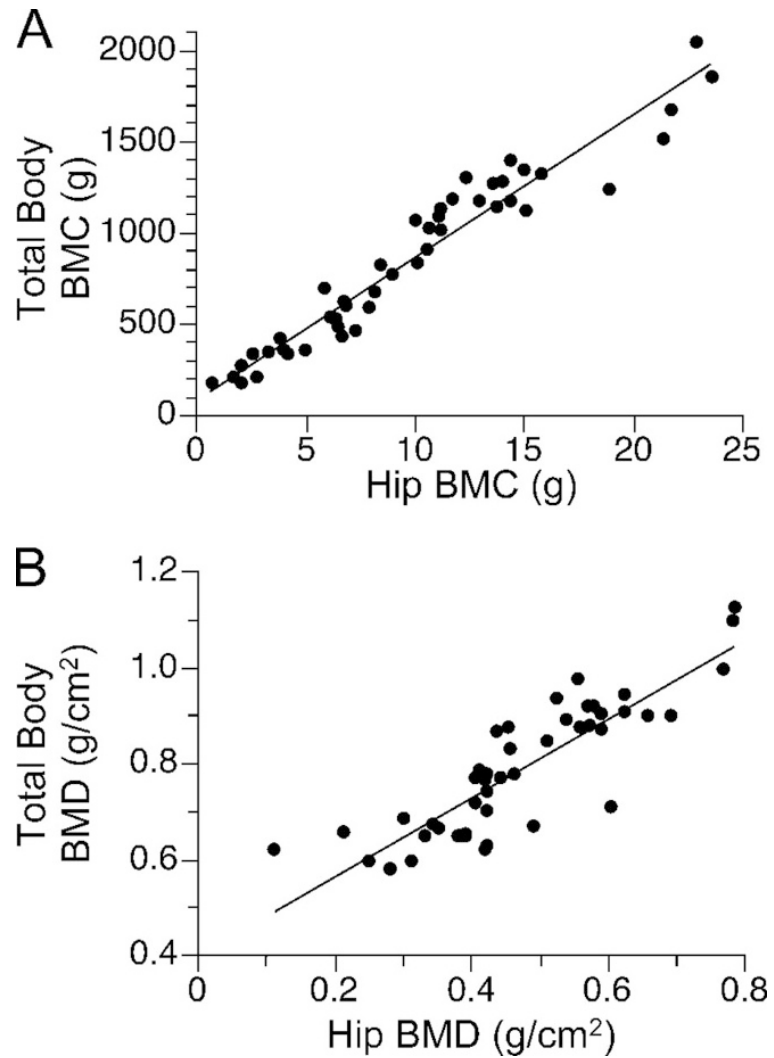

Figure 3. Relation between total body and hip BMC or BMD in girls and women $(n=50)$ with Rett syndrome: $(A)$ total body $\mathrm{BMC}_{(\mathrm{g})}=89+78$ hip $\left.\mathrm{BMC}_{(\mathrm{g})} ; p<0.001, r=0.97\right] ;(B)$ total body $\mathrm{BMD}_{\left(\mathrm{g} / \mathrm{cm}^{2}\right)}=0.40+0.82$ hip $\mathrm{BMD}_{\left(\mathrm{g} / \mathrm{cm}^{2}\right)} ; p<0.001, r=0.86$.

Table 3. Total body BCM and BMD z scores vs the presence or absence of skeletal fractures, scoliosis, seizures, anticonvulsant use, and ambulatory status in girls and women $(n=50)$ with Rett syndrome

\begin{tabular}{lccc}
\hline Variable & No. subjects & BMC $z$ score* & BMD $z$ score* \\
\hline Presence of seizures & & & \\
$\quad$ Yes & 32 & $-2.4 \pm 1.0 \dagger$ & $-2.0 \pm 1.1$ \\
$\quad$ No & 17 & $-1.8 \pm 0.9$ & $-1.3 \pm 1.2$ \\
Ever used anticonvulsants & & \\
$\quad$ Yes & 34 & $-2.4 \pm 0.9 \ddagger$ & $-2.1 \pm 1.0 \ddagger$ \\
$\quad$ No & 15 & $-1.5 \pm 0.9$ & $-1.0 \pm 1.3$ \\
Currently using anticonvulsants & & \\
$\quad$ Yes & 25 & $-2.2 \pm 1.2$ & $-1.8 \pm 1.3$ \\
$\quad$ No & 24 & $-2.1 \pm 0.8$ & $-1.6 \pm 1.1$ \\
Presence of scoliosis & & & \\
$\quad$ Yes & 31 & $-2.4 \pm 1.0$ & $-2.0 \pm 1.1 \dagger$ \\
$\quad$ No & 18 & $-1.8 \pm 1.0$ & $-1.3 \pm 1.3$ \\
Ever walked & & & \\
Yes & 42 & $-2.2 \pm 1.0$ & $-1.9 \pm 1.0$ \\
$\quad$ No & 7 & $-1.9 \pm 1.2$ & $-0.6 \pm 1.5$ \\
Currently walks without assistance & & \\
$\quad$ Yes & 37 & $-2.2 \pm 0.9$ & $-1.9 \pm 1.0$ \\
$\quad$ No & 12 & $-2.2 \pm 1.3$ & $-1.2 \pm 1.7$ \\
Occurrence of skeletal fractures & & \\
$\quad$ Yes & 13 & $-3.0 \pm 0.9 \S$ & $-2.6 \pm 1.0 \ddagger$ \\
No & 36 & $-1.8 \pm 0.9$ & $-1.4 \pm 1.1$ \\
\hline
\end{tabular}

$*$ Values expressed as mean $\pm \mathrm{SD}$.

$\dagger p<0.05$.

$\ddagger p<0.01$.

$\S p<0.001$ scoliosis $(18.0 \pm 8.9$ versus $11.0 \pm 9.5 \mathrm{y}, p<0.01)$ were older. Fractures were found in $50 \%$ of females with, but only in $7 \%$ of those without, bone mineral deficits $\left(\chi^{2}=11.3, p<0.001\right)$. Total body BMC and BMD $z$ scores were significantly lower in those with than without fractures (Table 3). Fractures ranged from one to five per individual and occurred at variable sites. Scoliosis was found in $77 \%$ of those with, and in $52 \%$ of those without, bone mineral deficits $\left(\chi^{2}=3.3, p<0.07\right)$. Total body BMD, but not BMC, $z$ scores were significantly lower in those with than without scoliosis (Table 3).

\section{DISCUSSION}

The natural history of bone mineral deficits and bonerelated disorders has not been characterized fully in females with RTT. In this cross-sectional study, low BMD was common, occurring in $45 \%$ of the RTT cohort. However, the variability across the age range studied precluded our ability to identify individual susceptibility. Although absolute BMC and BMD increased with advancing age, BMC and BMD $z$ scores were lower in older than in younger females. Skeletal fractures and scoliosis also were common, occurring in 28 and $64 \%$, respectively, of the RTT cohort, and were associated with lower total body BMC and BMD. Bone mineral deficits were identified across a broad range of MECP2 mutations. These findings highlight the importance of early diagnosis of bone mineral deficits in RTT and underscore the need to better understand the molecular mechanisms of MECP2 in the regulation of bone mineral metabolism.

BMC in healthy, prepubertal and postpubertal children increases annually by $11 \pm 2 \%$ and $4 \pm 0.5 \%$, respectively (16). In the present study, the rate of increase in total body BMC and BMD in females with RTT was substantially lower than that of healthy, unaffected girls, aged $8-16$ y (13), but paralleled changes observed in children with other neurologic disabilities $(15,17)$. Others have reported deficits in cortical bone thickness, radial bone density, and tibial bone strength, measured by skeletal radiographs, densitometry, and ultrasonography in girls with RTT $(3,18,19)$. Histomorphometric studies of trabecular bone in girls with RTT suggest that deficits in BMD may be the consequence of decreased bone formation rather than increased resorption because the number and metabolic activity of osteoblasts are decreased, while the number of osteoclasts may be normal or diminished (20). Thus, bone mineral deficits in RTT may be a manifestation of growth failure rather than a degenerative disorder (17).

Although bone mineral deficits were apparent at an early age, we found marked variability in total body BMC and BMD among the RTT cohort. Genetic factors are thought to be responsible for $70 \%$ of the variance in bone mass (21). However, the variability in total body BMC or BMD in the RTT cohort could not be explained by their mutations because the small number of subjects within each group precluded phenotype-genotype correlations. Others have suggested that $\mathrm{R} 133 \mathrm{C}$ and T158M mutations confer a protective effect against bone mineral deficits (19), but we did not observe such an effect. In the present study, deficits in lean body mass, but not body fat, paralleled bone mineral deficits (22). Being 
African American, as in unaffected individuals, tended to protect against low bone density (13). BMC and BMD $z$ scores were lower in individuals who had seizures and received anticonvulsants, both known risk factors (15).

Ambulation protects against bone mineral deficits in children with neurologic disorders (23). In children with cerebral palsy, programs using upright stands, load-bearing physical activities, or vibrating platforms improved vertebral, femoral neck, and tibial BMD (24-26). In our study, however, total body BMC and BMD $z$ scores were not significantly different between those who ambulated independently and those who walked with assistance or never walked. The explanation for this finding was not readily apparent although, in contrast to other studies (23), body size did not differ between our ambulatory and nonambulatory groups. Despite our findings, we routinely emphasize physical therapy for females with RTT to improve their functional abilities (27).

Low BMD is thought to contribute to fracture risk, although prospective measures of BMD in the lumbar spine of children with cerebral palsy did not predict subsequent fracture risk (28). In healthy girls, each $1 \mathrm{SD}$ reduction of total body BMD doubles the risk for new fractures (29). The annual fracture rate for healthy females $6 \mathrm{y}$ of age and older is 3 per 100 person-y (30) and for girls with spastic quadriplegia, 2.7 per 100 person-y (28). In the present study, one to five skeletal fractures occurred in $28 \%$ of the RTT cohort, resulting in a fracture rate of 3.6 per 100 person-y. Scoliosis occurred in $64 \%$ of the RTT cohort, a value in the range of other reports (31-34). However, we may have underestimated the prevalence of scoliosis and the severity of low BMD in females with RTT because we excluded females with spinal rod placement. Nevertheless, for future DXA applications, the correlation among spine, hip, and total body BMC and BMD in the RTT cohort is of practical importance for those in whom repetitive movements or spinal rod placement preclude total body scans. The associations among low BMC and BMD, fractures, and scoliosis suggest that bone mineral metabolism is important for bone mineral health.

In summary, bone mineral deficits and bone-related disorders were common in RTT. Bone mineral deficits were greater in older than in younger females with RTT. Fractures and scoliosis were associated with lower BMC and BMD. Although factors commonly associated with protection from, or increased risk of, bone mineral deficits were identified, a better understanding of molecular mechanisms that regulate the interaction between $M E C P 2$ and bone mineral metabolism is crucial to the development of therapeutic strategies for RTT.

Acknowledgments. The authors thank J. Kenard Fraley and E. O'Brian Smith for assistance with data management and statistical analysis, and the families who permitted their daughters to participate in this study.

\section{REFERENCES}

1. Haas RH, Dixon SD, Sartoris DJ, Hennessy MJ 1997 Osteopenia in Rett syndrome J Pediatr 131:771-774

2. Leonard H, Thomson M, Bower C, Fyfe S, Constantinou J 1995 Skeletal abnormalities in Rett syndrome: increasing evidence for dysmorphogenetic defects. Am J Med Genet 58:282-285
3. Leonard H, Thomson MR, Glasson EJ, Fyfe S, Leonard S, Bower C, Christodoulou J, Ellaway C 1999 A population-based approach to the investigation of osteopenia in Rett syndrome. Dev Med Child Neurol 41:323-328

4. Amir RE, Van den Veyer IB, Schultz R, Malicki DM, Tran CQ, Dahle EJ, Philippi A, Timar L, Percy AK, Motil KJ, Lichtarge O, Smith EO, Glaze DG, Zoghbi HY 2000 Influence of mutation type and X chromosome inactivation on Rett syndrome phenotypes. Ann Neurol 47:670-679

5. Motil KJ, Schultz RJ, Abrams S, Ellis KJ, Glaze DG 2006 Fractional calcium absorption is increased in girls with Rett syndrome. J Pediatr Gastroenterol Nutr 42:419-426

6. Ellis KJ, Shypailo RJ, Hardin DS, Perez MD, Motil KJ, Wong WW, Abrams SA $2001 \mathrm{Z}$ score prediction model for assessment of bone mineral content in pediatric diseases. J Bone Miner Res 16:1658-1664

7. Trevathan E, Moser HW 1988 Diagnostic criteria for Rett syndrome. Ann Neurol 23:425-428

8. Villard L 2007 MECP2 mutations in males. J Med Genet 44:417-423

9. Huppke P, Held M, Hanefeld R, Engel W, Laccone F 2002 Influence of mutation type and location on phenotype in 123 patients with Rett syndrome. Neuropediatrics 33:63-68

10. U.S. Department of Health and Human Services. National Center for Health Statistics. National Health and Nutrition Examination Survey. Available at: http:// www.cdc.gov/growthcharts. Accessed January 28, 2008

11. Durnin JV, Rahaman MM 1967 The assessment of the amount of fat in the human body from measurements of skinfold thickness. Br J Nutr 21:681-689

12. Greulich WW, Pyle SI 1959 Radiographic Atlas of Skeletal Development of the Hand and Wrist. Stanford University, Palo Alto

13. Ellis KJ, Abrams SA, Wong WW 1997 Body composition of a young, multiethnic female population. Am J Clin Nutr 65:724-731

14. Compston JE 1995 Bone density: BMC, BMD, or corrected BMD? Bone 16:5-7

15. Henderson RC, Lark RK, Gurka MJ, Worley G, Fung EB, Conaway M, Stallings VA, Stevenson RD 2002 Bone density and metabolism in children and adolescents with moderate to severe cerebral palsy. Pediatrics 110:e5

16. Braillon PM 2003 Annual changes in bone mineral content and body composition during growth. Horm Res 60:284-290

17. Henderson RC, Kairalla JA, Barrington JW, Abbas A, Stevenson RD 2005 Longitudinal changes in bone density in children and adolescents with moderate to severe cerebral palsy. J Pediatr 146:769-775

18. Cepollaro C, Gonnelli S, Bruni D, Pacini S, Maritni S, Franci MB, Gennari L, Rossi S, Hayek G, Zappella M, Gennari C 2001 Dual x-ray absorptiometry and bone ultrasonography in patients with Rett syndrome. Calcif Tissue Int 69:259-262

19. Zysman L, Lotan M, Ben-Zeev B 2006 Osteoprosis in Rett syndrome: a study on normal values. Scientific World Journal 6:1619-1630

20. Budden SS, Gunness ME 2003 Possible mechanisms of osteopenia in Rett syndrome: bone histomorphometric studies. J Child Neurol 18:698-702

21. Slemenda CW, Christian JC, Williams CJ, Norton JA, Johnston CC Jr 1991 Genetic determinants of bone mass in adult women: a reevaluation of the twin model and the potential importance of gene interaction on heritability estimates. J Bone Miner Res 6:561-567

22. Glastre C, Braillon P, David L, Cochat P, Meunier PJ, Delmas PD 1990 Measurement of bone mineral content of the lumbar spine by dual energy x-ray absorptionetry in normal children: correlations with growth parameters. J Clin Endocrinol Metab 70:1330-1333

23. Chad KE, McKay HA, Zello GA, Bailey DA, Faulkner RA, Snyder RE 2000 Body composition in nutritionally adequate ambulatory and non-ambulatory children with cerebral palsy and a healthy reference group. Dev Med Child Neurol 42:334-339

24. Caulton JM, Ward KA, Alsop CW, Dunn G, Adams JE, Mughal MZ 2004 A randomized controlled trial of standing programme on bone mineral density in non-ambulant children with cerebral palsy. Arch Dis Child 89:131-135

25. Chad KE, Bailey DA, McKay HA, Zello GA, Snyder RE 1999 The effect of a weight-bearing physical activity program in bone mineral content and estimated volumetric density in children with spastic cerebral palsy. J Pediatr 135:115-117

26. Ward K, Alsop C, Caulton J, Rubin C, Adams J, Mughal Z 2004 Low magnitude mechanical loading is osteogenic in children with disabling conditions. J Bone Miner Res 19:360-369

27. Lotan M, Isakov E, Merrick J 2004 Improving functional skills and physical fitness in children with Rett syndrome. J Intellect Disabil Res 48:730-735

28. Henderson RC 1997 Bone density and other possible predictors of fracture risk in children and adolescents with spastic quadriplegia. Dev Med Child Neurol 39: $224-227$

29. Goulding A, Jones IE, Taylor RW, Manning PJ, Williams SM 2000 More broken bones: a 4-year double cohort study of young girls with and without distal forearm fractures. J Bone Miner Res 15:2011-2018

30. Grazier KL, Holbrook TL, Kelsey JL, Stauffer RN 1984 The frequency of occurrence, impact, and cost of musculoskeletal conditions in the United States. American Academy of Orthopedic Surgeons, Chicago, pp 72-80

31. Kerr AM, Webb P, Prescott RJ, Milne Y 2003 Results of surgery for scoliosis in Rett syndrome. J Child Neurol 18:703-708

32. Harrison DJ, Webb PJ 1990 Scoliosis in the Rett syndrome: natural history and treatment. Brain Dev 12:154-156

33. Bassett GS, Tolo VT 1990 The incidence and natural history of scoliosis in Rett syndrome. Dev Med Child Neurol 32:963-966

34. Ager S, Fyfe S, Christodoulou J, Jacoby P, Schmitt L, Leonard H 2006 Predictors of scoliosis in Rett syndrome. J Child Neurol 21:809-813 